
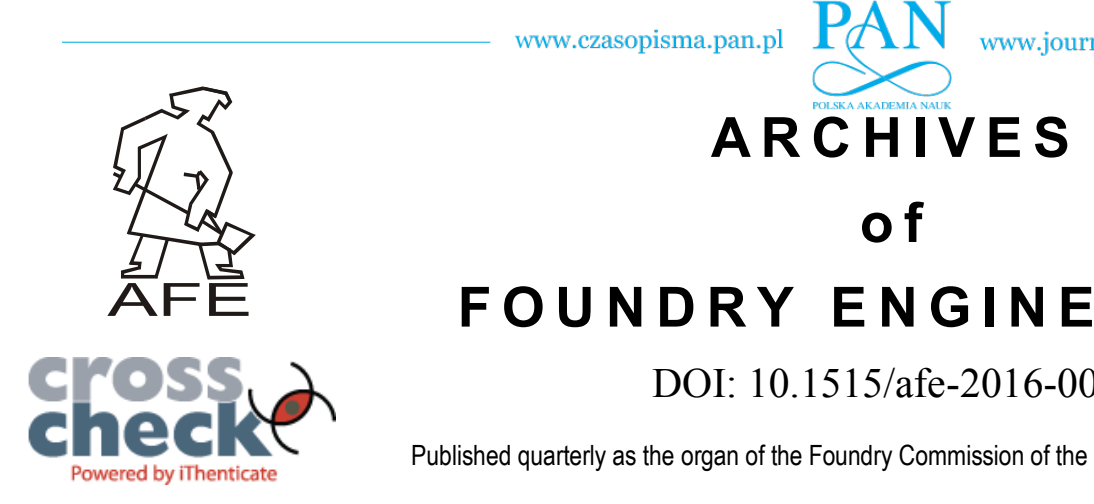

ARCHIVES

\title{
Influence of Tin Bronze Melting and Pouring Parameters on Its Properties and Bells' Tone
}

\author{
D. Bartocha *, C. Baron \\ Department of Foundry Silesian University of Technology, ul. Towarowa 7, 44-100 Gliwice Poland \\ *Corresponding author. E-mail: dariusz.bartocha@polsl.pl
}

Received 06.04.2016; accepted in revised form 30.06.2016

\begin{abstract}
The most important feature of bells is their sound. Its clarity and beauty depend, first of all, on the bell's geometry - particularly the shape of its profile, but also on the quality of alloy used to its cast. Hence, if the melting and pouring parameters could influence the alloy's properties, what influence they would have on the frequencies of bell's tone. In the article authors present their own approaches to find answers on that and more questions.
\end{abstract}

Keywords: Tin Bronzes, Parameters of melting and pouring, Bell's Tone

\section{Introduction}

The bell is a peculiar kind of art casting, it may be said that it is double art. On the one hand the bell should be regarded as a kind of sculpture, mainly in terms of the so-called graphic layout The shape and proportion of whole bell's solid is also very important. The perfect example of modern bell's graphic layout may be the new bells of Cathedral Notre Dame in Paris (Fig. 1). On the other hand the bell is a musical instrument. The whole craftsmanship of making bells lies in the fact that beside the beautiful shape and decorations, they emit clean and pleasant to the ear sound. Only the bell that fulfills both of these conditions, deserves to the art casting titre. A beautiful bell but with an unclean sound is not a proper bell. But despite the perfect tone, a bell designed in Australia might be regarded as a full value bell. Finite element analysis was used to design this bell with particular tonal qualities, which was then cast in moulds made using numerical controlled tools. The bell was designed on a number of different principles, such as to have harmonic partials or multiple pitches a planned interval apart. The profiles of this bell are complex as can been seen from Figure $2[1,2]$.

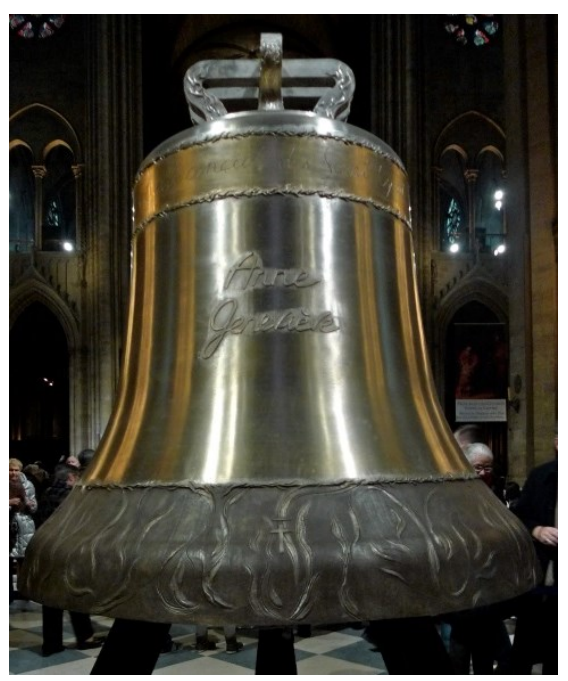

Fig. 1. Anne-Geneviève one of the new bells of Cathedral Notre Dame in Paris 


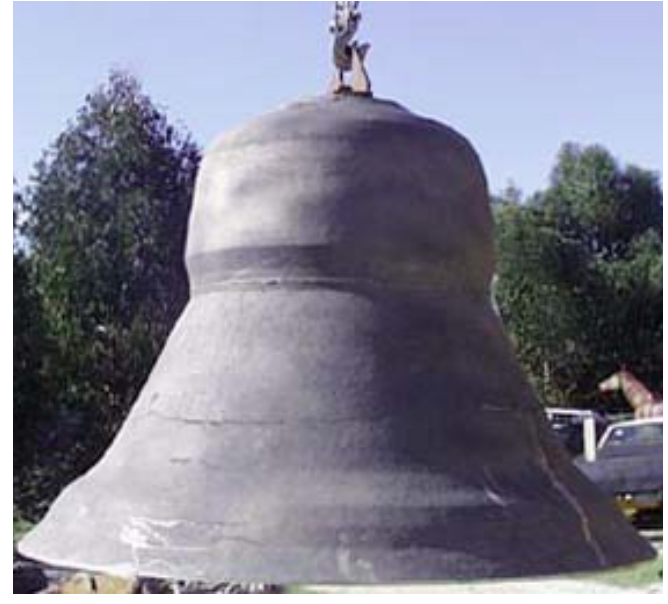

Fig. 2. Special profile of polytone bell by Australian Bell [2]

Church bells are type of idiophone, in which a tuning process is used to give closely harmonic modes.

Tuning process consists of minor adjustment by turn metal off the inside of the bell at specific places $[4,5]$. Bell tuning is as much art as science, because removing metal from a particular annular circle inside the bell, affects the frequencies of multiple partials in different ways. Also, metal once removed cannot be replaced. Lehr [6] provides details of experiments showing how each partial is affected by removal of metal at various points.

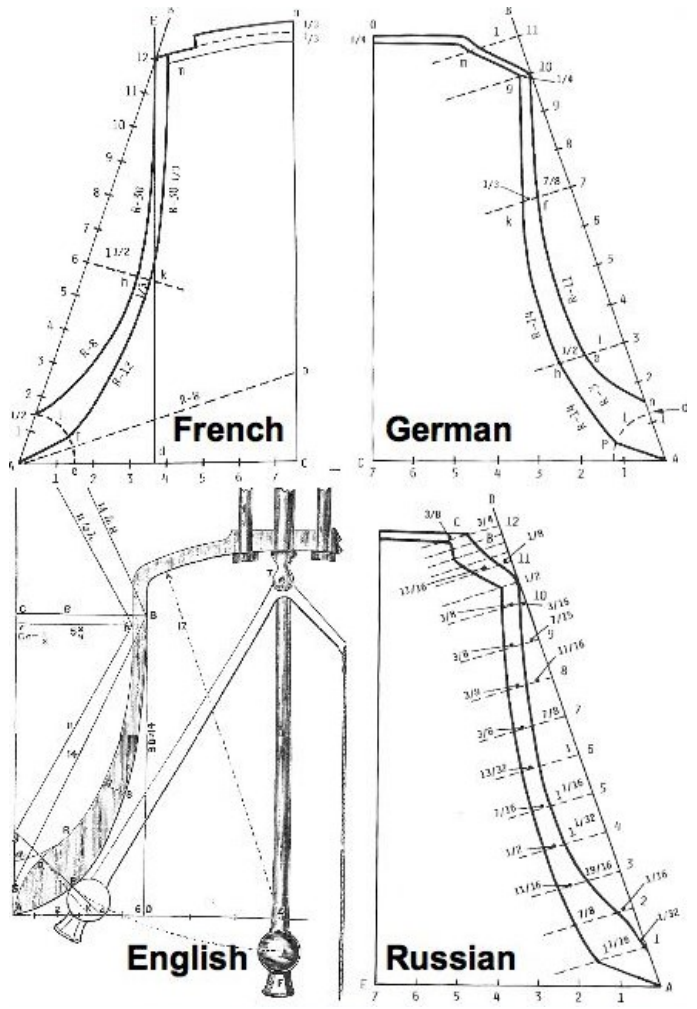

Fig. 3. The shape of bell's profile
In the case of bells, the general pattern of mode frequencies is fixed by the so called profile [3], which is different in spite of its origin, the most popular profiles are shown in figure 3 . The target frequencies for the first few modes are in the ratios $0.5: 1.0: 1.2$ : $1.5: 2.0 \ldots$ and these can be quite closely matched. The first mode, called the hum, is not prominent, and the perceived pitch is usually that of the second mode or 'prime', perhaps because it is reinforced by the harmonically-related modes with relative frequencies 2, 3 and 4 . The tone is complex, particularly because of the presence of the minor-third interval 1.2. The sound of bells playing in harmony is therefore, to say the least, 'characteristic'.

The vibration of bells is essentially linear because of their great wall stiffness, but there is nevertheless one nonlinear aspect of the produced sound. This arises because the first mode, which is responsible for the hum tone, has a shape in which the axial cross-section of the bell oscillates between two ellipses oriented at right angles to each other. Since the area enclosed by an ellipse is smaller than that enclosed by a circle of the same perimeter, this oscillation at frequency fl moves air in and out of the bell's mouth at frequency $2 \mathrm{fl}$ and generates a tone that reinforces the prime [3].

One other feature of bell's vibration is worth mentioning, and that is that all the modes noted above are actually doubly degenerated because of the rotational symmetry of the bell. In practice this symmetry is unlikely to be exact, so the degeneracy is lifted and each mode actually consists of a closely spaced doublet, and these generally produce very slow beats that are clearly audible.

A number of factors affect the amplitude of the various partials in the sound of a bell. These include:

- Mechanical characteristics of the bell, i.e. its shape and wall thickness and the composition of the metal,

- The clapper material and the dynamics of the impact as the clapper hits the Bell,

- The acoustics of the room or building in which the bell is housed.

Perception of loudness of sounds in the ear also varies with frequency.

Perrin et al [4] identified 134 modes of vibration, many of which were doubleted giving almost twice this many partials. Each mode of vibration was identified by comparing experimental results with a computer simulation of the bell structure. However the properties of bell's material used in simulation are not introduced.

Gołaś et al [7] in own calculation adopted the following properties of bell's material: the Young module of $1.05 \mathrm{E}+5 \mathrm{MPa}$, the Poisson ratio of 0.33 and density of $8600 \mathrm{~kg} / \mathrm{m} 3$. They analyzed only three partials: hum, prime and third, differences in obtained frequencies compared to perfect tuned are quite big. Expressing the difference between the frequencies in cents, it is evident that in musical terms the interval between hum and prime modes differs from perfect octave by about 2 semitones (201 cents), while the interval between minor third and prime differs from perfect minor third by about $3 / 4$ semitones ( 76 cents).

According to the equation (1) natural frequencies are the function of geometry (shape of profile) and properties of material with which the bell was made. Therefore, in modal analysis (natural frequencies determination) or designing (new profile, bell scaling) based on numerical simulation, the fundamental is 
validation of the model, taking into account material properties. Especially because both the material properties and bell's geometry depend of molding, melting and casting processes.

$$
\left([K]-\omega_{i}^{2}[M]\right)\left\{\varphi_{i}\right\}=\{0\}
$$

Where:

$[\mathrm{K}]$ - stiffnes matrix,

$[\mathrm{M}]$ - mass matrix,

$\omega$ - natural frequencies,

$\varphi$ - mode shapes.

How big the differences between frequencies of measured and calculated partials can be? To answer this question, the authors have carried out simple experiment. It consists of measuring profile of well-tuned bell on bridge-type measuring machine ZAISS Acura 7. The carillon bell without any graphic layout, $\mathrm{c}^{3}$ tone was used. On the basis of measurement the geometric model of the bell was performed and next it was subjected to modal analysis with ANSYS Modal. Calculated characteristic own frequencies of bell were compared with partials obtained in analysis of bell sound. Analysis by Fourier transform were performed with Wavanal software created by Bill Hibbert. The partials chosen are those which determine the strike pitch, the lowest five partials (hum, prime, tierce, quint and nominal), which are traditionally tuned by bellfounders, and other prominent partials as seen in Figure 4.

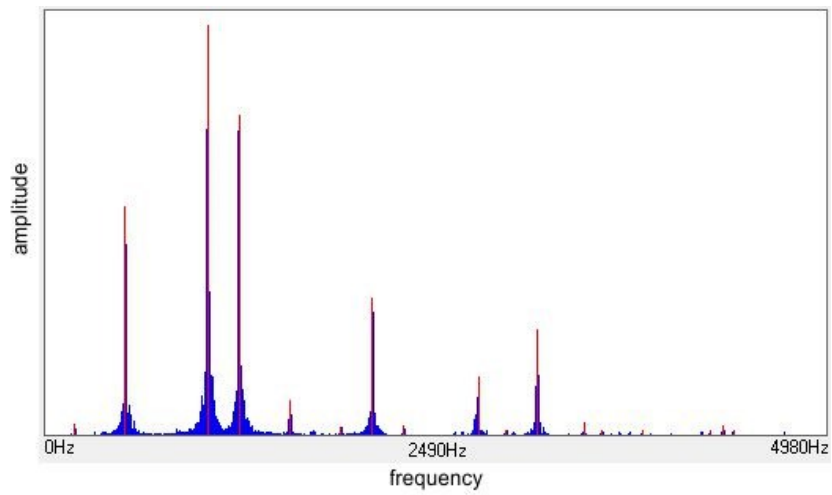

Fig. 4. Frequencies of prominent partials determined for tested bell

Mode shapes affecting chosen partials of the bell sound were determined accordingly to the literature [4] The results are presented in Fig. 5.

Modal analysis was performed for material properties of bell bronze accordingly with, in first step ASTM standard (UNS C91300) and in second [7]. Next the materials properties had been changed to obtain frequencies of partials as near the measured ones as possible, the arbitrary partial was nominal. In first approach only Young's modulus (E) was changed, in second only density $(\rho)$ and in third Poisson's ratio $(v)$. All obtained results are presented in Table 1, except ones for Poisson's ratio because even the absurd values of ratio were applied, the required frequency was not obtained. a)
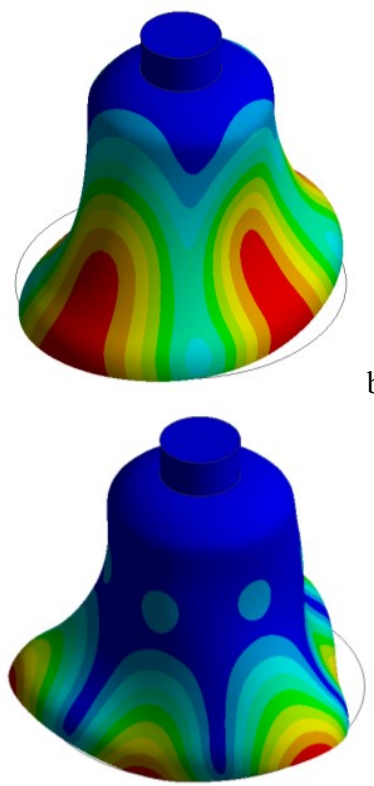

c)

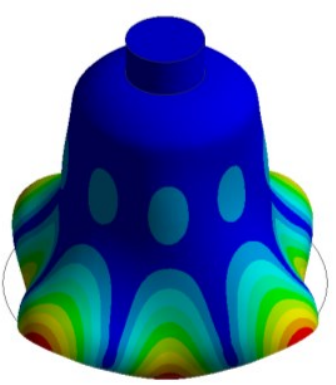

e)

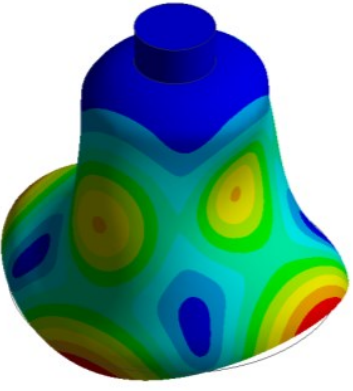

d)

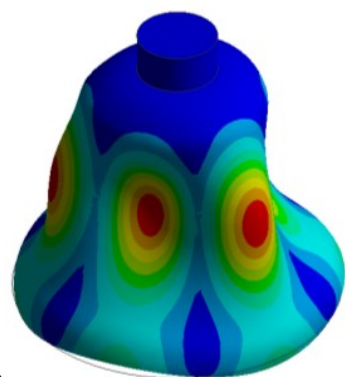

f)
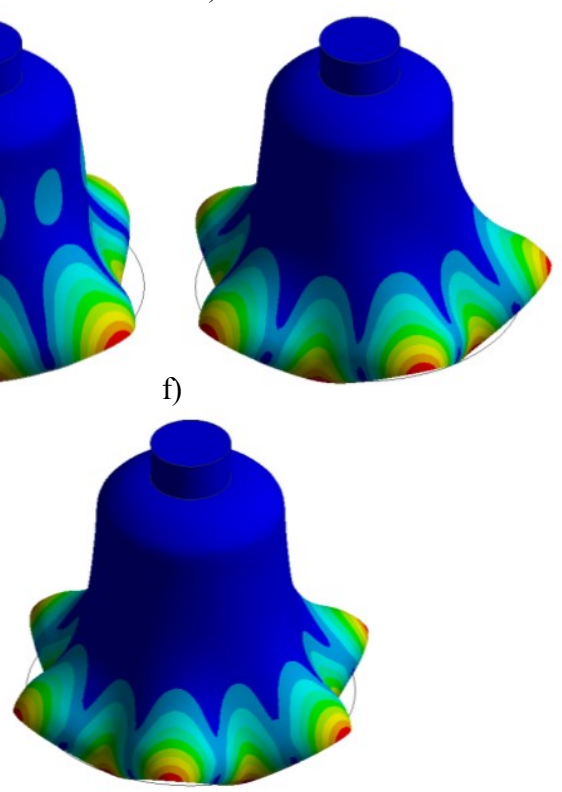

g)

Fig. 5. Mode shapes affecting partials: a) hum, b) prime, c) tierce, d) quint, e) nominal, f) super-quint and g) octave nominal. 
Table 1.

The frequencies in $[\mathrm{Hz}]$ of the main partials

\begin{tabular}{|c|c|c|c|c|c|c|c|}
\hline & Hum & Prime & Tierce & Quint & Nominal & $\begin{array}{c}\text { Super- } \\
\text { quint }\end{array}$ & $\begin{array}{c}\text { Octave } \\
\text { Nominal } \\
\end{array}$ \\
\hline Ratios based on Prime & 0,5 & 1 & 1,2 & 1,5 & 2 & 3 & 4 \\
\hline Calculated on measured prime & 523,5 & 1047 & 1256,4 & 1570,5 & 2094 & 3141 & 4188 \\
\hline $\begin{array}{c}\text { Measured } \\
\text { (Fig. 4) }\end{array}$ & 519.5 & 1047 & 1246 & 1565 & 2087.5 & 3134.5 & 4316 \\
\hline $\begin{array}{c}\text { ET } 12 \\
\text { Equal Temperament }\end{array}$ & $\begin{array}{c}c^{2} \\
523.25\end{array}$ & $\begin{array}{c}c^{3} \\
1046.5\end{array}$ & $\begin{array}{c}\operatorname{dis}^{3} \\
1244.5\end{array}$ & $\begin{array}{c}\mathrm{g}^{3} \\
1567.98\end{array}$ & $\begin{array}{c}c^{4} \\
2093\end{array}$ & $\mathrm{~g}^{4} 3135,96$ & $\begin{array}{c}c^{5} \\
4186 \\
\text { cis }^{5} \\
4434,92 \\
\end{array}$ \\
\hline $\begin{array}{c}\text { Calcualted } \\
\text { Ansys Modal } \\
\text { UNS C } 91300\end{array}$ & 537.4 & 1088.3 & 1278.6 & 1608.1 & 2144.6 & 3212 & 4424.5 \\
\hline $\begin{array}{c}\text { Calcualted } \\
\text { Ansys Modal } \\
{[7]}\end{array}$ & 530.09 & 1075.6 & 1263.1 & 1587.8 & 2119.4 & 3175.3 & 4374.6 \\
\hline $\begin{array}{c}\text { Calcualted } \\
\text { Ansys Modal } \\
\text { (validated) } \\
\text { E }\end{array}$ & 522.1 & 1059.4 & 1244.1 & 1563.8 & 2087.5 & 3127.1 & 4308.5 \\
\hline $\begin{array}{c}\text { Calcualted } \\
\text { Ansys Modal } \\
\text { (validated) } \rho\end{array}$ & 522.1 & 1059.4 & 1244.1 & 1563.8 & 2087.5 & 3127.2 & 4308.7 \\
\hline $\begin{array}{c}\text { Calcualted } \\
\text { Ansys Modal } \\
\text { (validated) } \\
\rho, \mathrm{E}\end{array}$ & 522.1 & 1059.4 & 1244.1 & 1563.8 & 2087.5 & 3127.1 & 4308.6 \\
\hline
\end{tabular}

Almost identical frequencies values of particular partials were obtained for two configurations of density and Young's module values: $8600 \mathrm{~kg} / \mathrm{m}^{3}, 1.0186 \mathrm{E}+5 \mathrm{MPa}$ and $8865 \mathrm{~kg} / \mathrm{m}^{3}, 1.05 \mathrm{E}+5$ $\mathrm{MPa}$. The Poisson ratio value in both cases was 0.33 . Despite that, the mutual relation of density and Young's module is the basis of Ashby charts and copper alloys in this chart occupy only a small area (Fig. 6) such relation, for bronzes and any other materials, cannot be used for exactly determining the value of one properties on the basis of second. According to different sources, the value of Young's module for tin bronzes, depends on consisting of tin and the other elements varies between $0.96-1.2 \mathrm{E}+5 \mathrm{MPa}$ and density $7400-8900 \mathrm{~kg} / \mathrm{m}^{3}$. On the density of tin bronzes, because they tendency to porosity [13], significantly influence the parameters of: melt process (time, temperature), liquid metal treatment (deoxidation, modification) [9-13], hence such a large range of density values. Thus, the melting process and preparation of the metal indirectly, and as is evident from the calculations can significantly affect tone of bells.

The fundamental question therefore is: how big the range of variation of density, depending on the melting parameters and liquid metal treatment, can be?

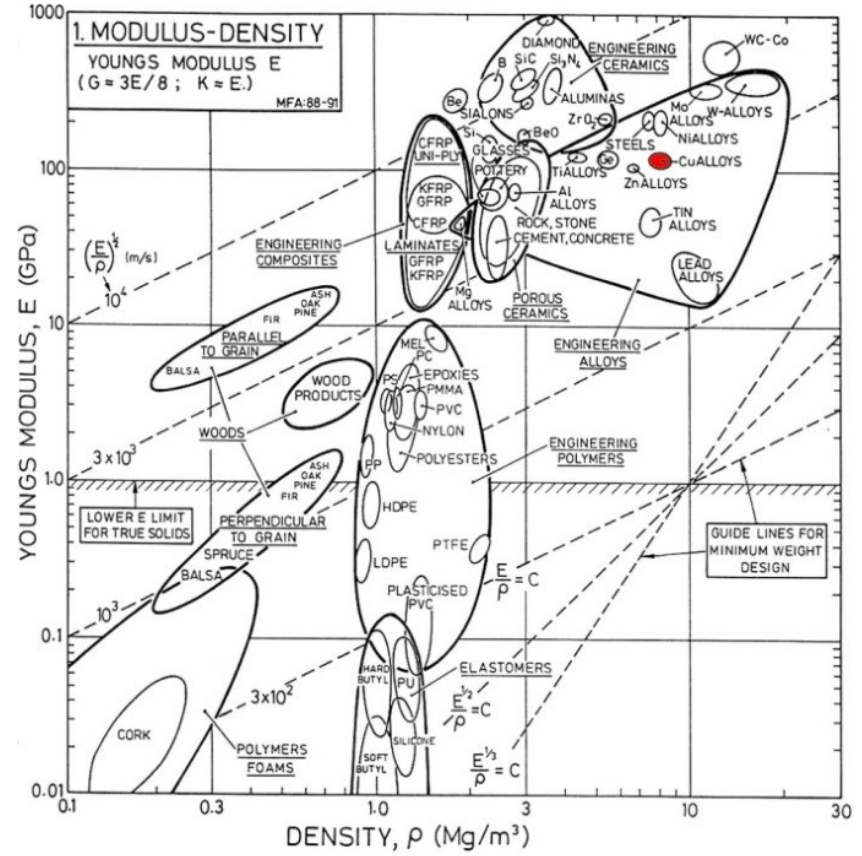

Fig. 6. Ashby chart 


\section{Experiment}

Trying to find the answer to the above question, the authors have conducted a number of experimental melts. Within each group of melts the changes of: type of initial (charge) material, overheating temperature, pouring temperature as well as refining and modifying additions, were controlled.

The first group of melts covers two melts that consisted on:

1. melting the charge materials and overheating the liquid metal to $1200^{\circ} \mathrm{C}$, next the furnace was turn off that liquid alloy was freely cooling down, started from $1200^{\circ} \mathrm{C}$ after each 50 degrees temperature was decreased a sample was cast, these samples are denoted as $\mathrm{CD}$,

2. melting the charge materials and overheating the liquid metal to $1000^{\circ} \mathrm{C}$, next liquid metal was being slowly heated up and started from $1000^{\circ} \mathrm{C}$ after each 50 degrees temperature was increased a sample was cast, these samples are denoted as CU,
Charge materials were technically pure OFHC cooper $(99,99 \%)$ and tin $(99,9 \%)$ in weight ratios $4: 1$.

The second group of melts were conducted identically as the first with only one difference - namely the charge material was a $\mathrm{CuSn} 20$ alloy prepared in advance by melting pure copper and tin. Samples cast within each melts are denoted SD and SU respectively.

The third group of melts were conducted accordingly to data given in table 2 , charge materials were technically pure cooper and tin as in first group of melts. A treatment method, amount and type of used material were selected on the basis of literature [912]. Alloy's temperature during metal batch treatment and pouring samples was in range $1050-1100^{\circ} \mathrm{C}$.

Table 2 .

Amount and type of substances used in the third series of melts.

\begin{tabular}{|c|c|c|c|c|c|c|}
\hline No of sample & $1 \mathrm{M}$ & $2 \mathrm{M}$ & $3 \mathrm{M}$ & $4 \mathrm{M}$ & $5 \mathrm{M}$ & $6 \mathrm{M}$ \\
\hline $\begin{array}{c}\text { Substance or the } \\
\text { way of } \\
\text { modification }\end{array}$ & - & $\begin{array}{c}\text { Raw stic } \\
45 \mathrm{~s}\end{array}$ & $\mathrm{CuP}$ & $\mathrm{Mg}$ & $\mathrm{Mn}+\mathrm{CaC}_{2}$ & Tophut \\
\hline $\begin{array}{c}\text { Weight of } \\
\text { metal/addition } \\
{[\mathrm{g}]}\end{array}$ & - & - & $3300 / 10$ & $2950 / 0.9$ & $2600 / 40+20$ & $2250 / 5$ \\
\hline
\end{tabular}

\section{Results}

On charts in figures $7-9$ the changes of density and hardness are shown. Both hardness and density were measured on samples cast during the experimental melts.

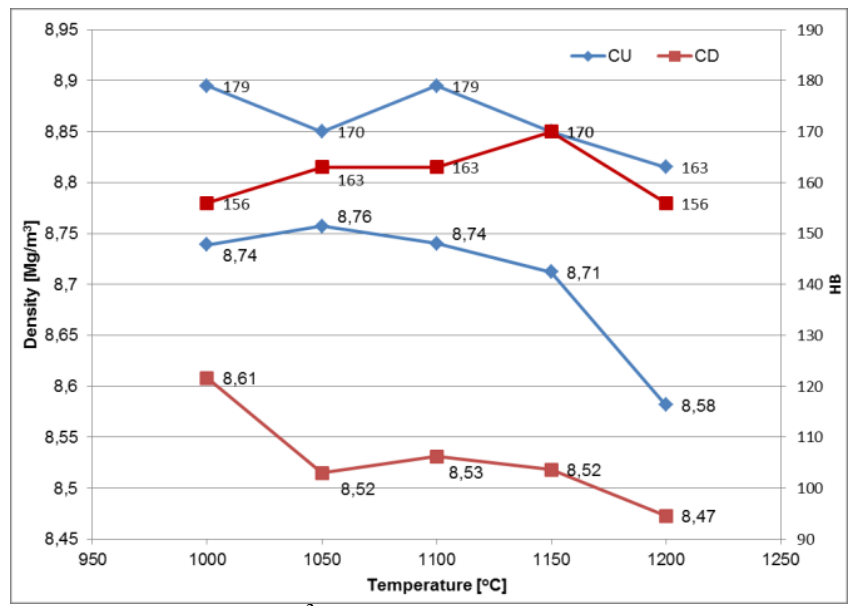

Fig. 7. Density $\left[\mathrm{Mg} / \mathrm{m}^{3}\right]$ and hardness HB changes of bronzes in first series of melts

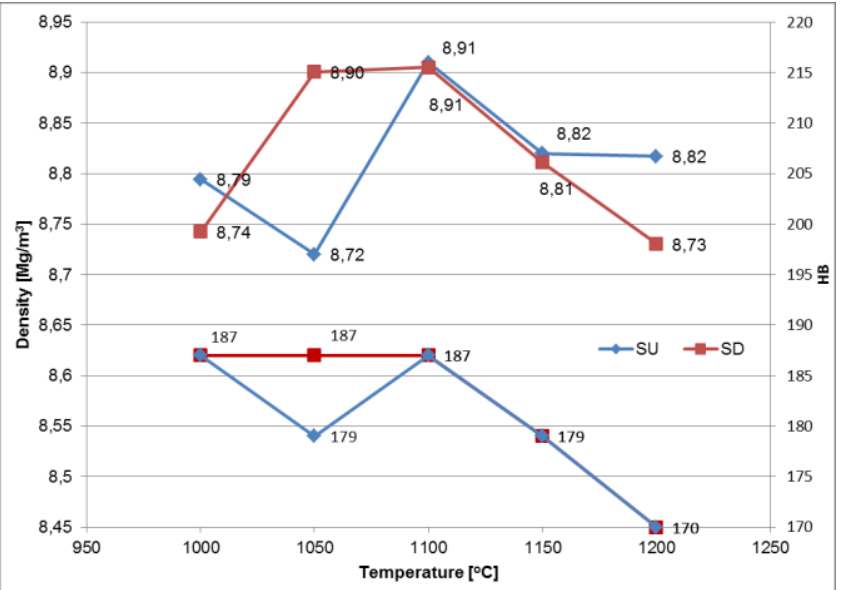

Fig. 8. Density $\left[\mathrm{Mg} / \mathrm{m}^{3}\right]$ and hardness HB changes of bronzes in second series of melts 


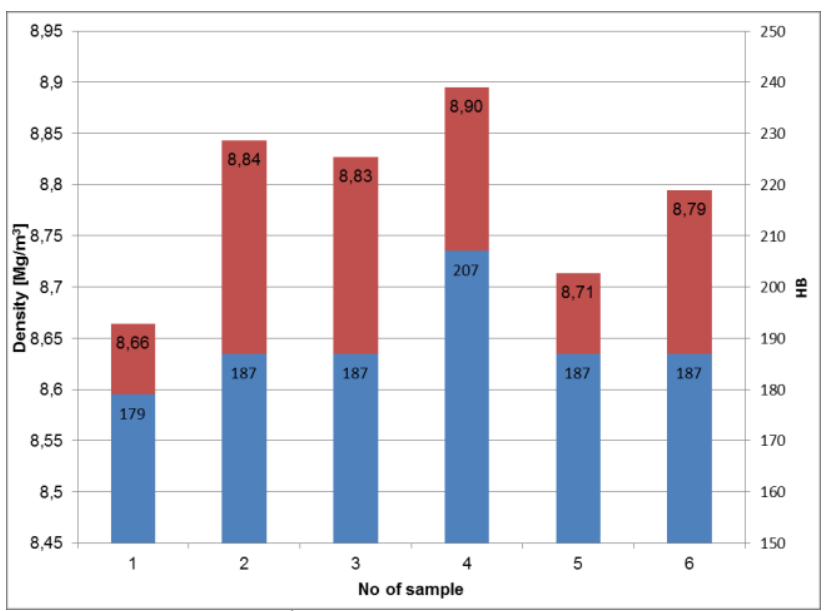

Fig. 9. Density $\left[\mathrm{Mg} / \mathrm{m}^{3}\right]$ and hardness HB changes of bronzes in third series of melts

\section{Discussion}

Influence of overheating and pouring temperatures on investigated bronze's density are significant, particularly in the case of the alloy melts directly from pure cooper and tin. The higher the pouring temperature, the lower the density of solid alloy in room temperature. This trend occurs for both in the case of lowering the temperature of the superheated bath as well as in the case of increasing the temperature of the alloy. Especially large impact on reducing final density had initial bath overheated.

Remelted alloy, used in second part of experiment, has not behaved in analogical way. Although decreasing of density and hardness was observed for increasing temperature, its relation is not unequivocal. A lack of significant differences in density and hardness of samples cast of overheated alloy and these cast of gradually heating alloy. Moreover both density and hardness of samples from second group of melts are clearly higher in compare with first group. Melting in advance of pure material probably caused alloy slightly impurifying. Impurities in crystallization process are acting as nucleus and decreasing its sensitivity to overheating and pouring temperature.

All of materials and operations used in third part of experiments have caused an increase in density and hardness, in comparison to a reference sample no $1 \mathrm{M}$. However, for all samples, obtained results are very near to these from second part of investigations obtained in the similar temperature. Slightly, among others, stand out particularly taking into account hardness the sample no $4 \mathrm{M}$, in its case the addition of magnesium to liquid metal was used. Because to high affinity of magnesium to oxygen applied, addition caused good bath deoxidation, what effected the lack of interdendritic micropores and formation of concentrated shrinkage cavity. What in the case of bells cast in traditional manner is unacceptable

\section{Conclusions}

The results of carried out investigations can be summarized as:

1.Preparation $\mathrm{CuSn} 20$ alloy directly from pure cooper and tin is not recommended. In case of such alloys the bath overheating causes significantly decreased density and hardness, which results in a significant discrepancy between the expected and obtained frequencies partials of bell's tone. In extreme cases we will not be able to properly tune the bell.

2.The alloy component pre-melting and preparation $\mathrm{CuSn} 20$ alloy as a charge material for target melt eliminates this tendency almost completely. However, it is not recommended for excessive overheating of the liquid alloy and the use of too high pouring temperature.

3.Liquid metal treatment should be reduced to necessary minimum, if the good quality charge materials are used generally it should be limited to protect bath surfaces against from the atmosphere influence.

\section{References}

[1] McLachlan, N., Cabrera, D., (2002). Calculated Pitch Sensations for New Musical Bell Designs, Proceedings of the 7th International Conference on Music Perception and Cognition, Sydney. 600-603.

[2] McLachlan, N., (2002). Sculpting Sound: New Bell Designs and Attitudes, Music Forum 8.

[3] Fletcher, N.H., (1999). The nonlinear physics of musical instruments. Rep. Prog. Phys. 62, 723-764.

[4] Perrin, R., Charnley, T. \& de Pont, J. (1983). Normal modes of the modern English church bell J. Sound Vibr. 90, 29-49.

[5] Rossing, T. D., \& Perrin, R. (1987). Vibration of bells Appl. Acoust. 20. 41-70.

[6] Lehr, A., (1965). Contemporary Dutch Bell-Founding Art; Hedendaagse Nederlandse Klokkengietkunst, Neth. Acoust. Soc. Publ. 7. 20-49.

[7] Gołaś, A. \& Filipek, R. (2009). Numerical Simulation for the Bell Directivity Patterns Determination. Arch. of Acoustics. 34(4), 415-427.

[8] Fletcher, N. H., Rossing, T.D. (1998). The Physics of Musical Instruments. Springer.

[9] Czochlarski, J., Bukowski, Z. (1935). Deoxidation of brasses and bronzes. Messages Institute of Metallurgy. Warszawa.

[10] Bydałek, A.W. (2009). The analysis of carbon attendance in copper alloys as reason of gas porosity. Archives of Foundry Engineering. 9(3), 25-28.

[11] Bydałek, A.W. (1999). The copper alloys melting in the reduction Conductions. Solidification of Metals and Alloys. $1(40), 87-92$.

[12] Bydałek, A.W. (2005). The analysis of the influence melting conduction copper alloys on the porousity. Archives of Foundry. 5(17), 27-36.

[13] Bartocha, D. \& Baron, C. (2015). „The Secret” of Traditional Technology of Casting Bells. Archives of Foundry Engineering. 15(si 3), 5-10. (in Polish). 